на нефтедобычу в шельфе Венесуэльского залива [9]. С 2018 года Россия производит инвестиции в нефтедобывающую отрасль страны. Национальный нефтяной консорциум, например, владеет 40\% акций в совместном СП Petromiranda, а Роснефть имеет 51\% в СП Perforosven [10]. Таким образом, Россия понесет значительные убытки если Венесуэла будет потеряна как рынок сбыта. Помимо экономической составляющей, нельзя не отметить составляющую политическую. Венесуэла на современном этапе поддерживает внешнеполитический курс России. Так Венесуэла была одним из немногих государств, которые признали независимость Абхазии и Южной Осетии в 2008 году, а в 2014 году Венесуэла признала Крым частью России [11].

Таким образом, нельзя недооценивать важность Венесуэлы как одного из самых лояльных современному российскому политическому курсу государств. Кроме непосредственной ценности, Венесуэла может служить важным опорным пунктом распространения российского влияния по всей Латинской Америке. Важный стратегический фактор, в совокупности с экономическим, сделает потенциальную «потерю» Венесуэлы болезненным ударом по позициям России не только в регионе, но и в целом на мировой арене. Именно поэтому России невыгодно любое обострение внутриполитической ситуации в Венесуэле, не говоря уже о гражданской войне, и Россия будет стремиться к максимально возможному урегулированию внутренних противоречий. Сохранение Венесуэлы в том формате, в котором она существует с самого начала XXI века, может оказаться еще более необходимым для Российской Федерации в условиях новой политической турбулентности в странах региона.

\section{Список литературы:}

1.President Annual Message. December 1823 // Library of Congress URL: https://memory.loc.gov/cgi- bin/ampage $?$ collId $=1$ lac \&fileName $=041 / 1 \mathrm{lac} 041 . \mathrm{db} \& \mathrm{r}$ ecNum=4 (дата обращения: 24.02.20)

2.Емельянов А.И. Геополитические интересы в Латинской Америке // Центр стратегических оценок и прогнозов URL: http://csef.ru/ru/politica-igeopolitica/326/geopoliticheskie-interesy-rossii-v-

latinskoj-amerike-4835 (дата обращения: 24.02.2020)

3.Страны мира. Краткий политикоэкономический справочник. М: Издательство политической литературы, 1981. С.367

4.Как Венесуэла строила «социализм XXI века» // РИА Новости URL: https://ria.ru/20190202/1550186417.html (дата обращения: 24.02.2020)

5.Неверов К.А., Мутагиров Д.3. «Левый поворот» в Латинской Америке и его влияние на международные политические процессы на континенте // диссертация на соискание научной степени. СПбГУ. С.138 - 139

6.Венесуэла: хроника кризиса социалистической модели // DW URL: https://www.dw.com/ru/венесуэла-хронологиякризиса-социалистической-модели/а-40013891 (дата обращения 24.02.20)

7.История политического кризиса в Венесуэле // TACC URL: https://tass.ru/info/6031159 (дата обращения 24.02.20) 2019

8.Парламентская газета, №13 (2879), С. 18.

9.Российско-венесуэльские отношения // МИД России URL: http://www.mid.ru/bdomp/nsrlat.nsf/601debeef6efe270432569dc002f680c/b9f4dc2 79d168151c3256e8b00411a30!OpenDocument (дата обращения: 24.02.20)

10. Российские интересы в Венесуэле // КоммерсантЬ URL: https://www.kommersant.ru/doc/3861747 (дата обращения: 24.02.20)

11. Чуркин: голосование в ГА ООН показало, что изоляции РФ нет // РИА Новости URL: https://ria.ru/20140327/1001348835.html\#ixzz2xBuC 3wK6 (дата обращения: 24.02.20)

УДК:316.344.24:37.015

ГРНТИ 04.51.53

АНАЛИЗ СОВРЕМЕННЫХ СОЦИАЛЬНЫХ ТЕХНОЛОГИЙ УПРАВЛЕНИЯ ЗНАНИЯМИ В ОБЩЕМ ОБРАЗОВАНИИ И ПРОБЛЕМ ИХ РЕАЛИЗАЦИИ

DOI: $10.31618 /$ ESU.2413-9335.2020.5.71.603

Дугина Кристина Альбертовна

Российская академия народного хозяйства и государственной службы при Президенте Российской Федераџии,

2. Екатеринбург

Соискатель

\title{
ANALYSIS OF MODERN SOCIAL TECHNOLOGIES FOR KNOWLEDGE MANAGEMENT IN THE SYSTEM OF GENERAL EDUCATION AND PROBLEMS OF THEIR IMPLEMENTATION
}

Dugina Kristina Albertovna

Russian Academy of nationaleconomy and public administration,

Ekaterinburg

Applicant 


\section{АННОТАЦИЯ}

Статья посвящена анализу социальных технологий управления знаниями с учетом специфики системы общего образования. Рассмотрены актуальные практики, обуславливающие особенности использования социальных технологий управления знаниями в системе общего образования, возможности и существующие проблемы управления знаниями, переживающей процесс модернизации и глобализации, с позиции социологической науки; в определении текущего состояния и продуктивности применения социальных технологий управления знаниями, перспектив и противоречий их развития, проблем реализации.

Проведенный анализ показал, что в настоящий момент внедрение социальных технологий управления знаниями в общем образовании находится еще на начальной стадии, по сравнению с зарубежной практикой, однако в то же время следует признать, что и в отечественной практике применяется ряд социальных технологий менеджмента знаний в образовании.

\section{ANNOTATION}

The article is devoted to the analysis of social technologies for knowledge management, taking into account the specifics of the general education system. Relevant practices that determine the features of the use of social knowledge management technologies in the general education system, the opportunities and existing problems of knowledge management, undergoing the process of modernization and globalization, from the perspective of sociological science are identified; in determining the current state and productivity of application of social technologies for knowledge management, prospects and contradictions of their development, implementation problems.

The analysis showed that at the moment, the introduction of social technologies for knowledge management in general education is still at the initial stage, compared with foreign practice, but at the same time it should be recognized that a number of social technologies for knowledge management in education are used in domestic practice.

Ключевые слова: социальные технологии, управление знаниями, общее образование.

Key words: social technologies, knowledge management, general education.

Сегодня развитие и модернизация системы общего образования в нашей стране характеризуется рядом специфических особенностей, которые стимулируют активный поиск новых путей повышения конкурентоспособности своих услуг и качества реализуемой образовательной деятельности, направлений комплексной реорганизации своих систем в условиях сложно протекающего процесса интеграция в европейское и общемировое образовательное пространство. Решение данных задач требует поиска новых концепций и парадигм функционирования системы общего образования и составляющих ее элементов, методических инструментов их реализации, в числе которых особую значимость приобретает концепция управления знаниями и обеспечивающие еe имплементацию социальные технологии.

В настоящий момент внедрение социальных технологий управления знаниями в общем образовании находится еще на начальной стадии, по сравнению с зарубежной практикой, однако в то же время следует признать, что и в отечественной практике применяется ряд социальных технологий менеджмента знаний в образовании [1], в ряду которых выделяются традиционные (диссеминация опытом и знаниями в рамках семинаров и тренингов, курсов повышения квалификации); совещания по анализу совместного опыта (в том числе в рамках проектов и экспериментальных площадок); конференции и совещания, направленные на выявление и решение общеорганизационных и методических проблем; конкурсы, ярмарки идей, профессиональные конференции, Дни профессиональных знаний; педагогические совещания и советы (короткие рассказы о «трудных случаях», рассказы о новых идеях и методах работы); «круглые столы», презентации (опыт конкретного педагога, методиста, управленца, методического объединения, учебного заведения и т.д.) - все данные технологии нацелены на поиск открытых инноваций и знаний как ключевую модель управления знаниями, стратегию персонализации знаний и стимулирование инновационной деятельности сотрудников; так и инновационные интерактивные методы проведения занятий, ориентация на работу в малых группах, индивидуализация учебных планов, соединение теоретических дисциплин, практических занятий и научно-исследовательской работы, развитие системы наставничества, элементы сторителлинга, дистанционное образование и т. д., стимулирующих внутренние коммуникации с целью управления знаниями.

Нужно отметить, что, в частности, особое распространение управление знаниями с использованием социальных технологий в условиях модернизации системы общего образования приобрело сегодня в российских условиях в рамках проектной деятельности. Данный подход предполагает интенсивный анализ опыта, накапливаемого в ходе того или иного проекта, реализуемого учебным заведением или педагогическим коллективом, и его тиражирование в других аналогичных проектах.

При запуске такого проекта проводится совещание по стандартной схеме, на котором члены группы отвечают на целый ряд вопросов, связанных с управлением знаниями по конкретной проблеме: 
1) какие знания нам нужны для того, чтобы данный проект (например, внедрение той или иной инновации в методику преподавания, образовательную среду учреждения, организацию обучения и воспитания) стал успешным?

2) где и от кого мы получим данные знания?

3) что мы должны сделать, чтобы получить эти знания?

4) когда мы это сделаем, и кто за это будет отвечать?

5) какого результата мы хотим добиться в конце?

Данная модель состоит в том, что обмен знаниями происходит во временной группе, состав которой меняется в зависимости от стадии проекта, дополняется элементами внешнего оценивания со стороны профессионального сообщества и других представителей социума с целью повышения качества конечного результата. Опыт проектной группы должен сознательно аккумулироваться усилиями ядра группы - постоянных членов команды, обеспечивающих преемственность выработанных договоренностей, сформированной методики описания опыта и совместно определенных целей. Нужно отметить, что в данных условиях эффективность управления знаниями в значительной степени зависит от распределения ролей между субъектами образовательного процесса, регулярности встреч и системы стимулирования. Например, руководители и участники проекта в рамках одной образовательной организации, могут быть дифференцированно премированы по итогам только после того, как будет завершена стадия систематизации результатов проекта в базе знаний, а руководитель проекта наравне с участниками выступит перед коллегами из других образовательных организациях города, округа, региона с презентацией итогов проекта, рассказом об извлеченных мероприятиях, уроков и рекомендациях на будущее.

Отметим, что в бизнес-среде часто (в российском общем образовании такие случаи пока еще редки, но данные идеи могут быть учтены на перспективу) выделяется специальная роль «менеджера знаний», ответственного за «сохранение» и «накопление» совместно выработанных идей и договоренностей, полученных результатов (знания), а также выполняющего экспертную роль. Первоначальное совещание по анализу опыта может быть средством кодификации накопленных знаний по заранее разработанной стандартной форме. Наиболее целесообразны такие «площадки» для обучения и обмена опытом в рамках определенной функциональной области (например, центр компетенций в области методических компетенций в области активных методов обучения; развития сетевого профессионального взаимодействия и т.п.). Однако такие центры могут представлять собой и специально созданные мобильные группы экспертов - педагогов, управленцев, родительской общественности и других представителей различных социальных групп. В число участников центров при этом включаются представители педагогического коллектива, демонстрирующие наиболее высокие результаты по ключевым показателям эффективности, которые способны накапливать и тиражировать свои знания и навыки на все остальные учебные заведения и регионы. После определенного периода практики такие центры могут получать довольно широкие полномочия: они могут выполнять независимый аудит текущей деятельности отдельных участков своего учебного заведения или других образовательных учреждений, инициировать изменения процессов и методик работы, накладывать вето на изменения организационной структуры и функционала сотрудников школы, если эти изменения не удовлетворяют требованиям центра компетенций. Социальная специфика данного подхода состоит в том, что в данном случае ответственность за управление знаниями несет конкретный трудовой коллектив с постоянным составом и общей судьбой, что способствует развитию качества образовательных услуг, предоставляемых учебным заведением в целом. Определенная сложность в данном случае заключается в том, что выявление и распространение передового опыта является здесь дополнительной задачей по отношению к основным функциональным обязанностям педагогов и управленцев образования, которые в большинстве случаев итак «перегружены» ежедневной работой. Однако в силу постоянства состава коллектива здесь на управление знаниями большое влияние оказывает степень сплоченности, используемый руководителем стиль руководства, сложившаяся в подразделении субкультура, а также сформировавшаяся ранее история отношений с коллективами других учебных заведений.

В тоже время, следует признать, что в российских учебных организациях системы общего образования социальные технологии во многом проявляются фрагментарно: пока еще отсутствует системный подход к использованию социальных технологий управления знаниями, согласованных со стратегическими целями и задачами системы общего образования в целом и его отдельных субъектов и объектов, что обусловлено, в том числе и незавершенностью реформ в сфере общего образования, множественностью элементов данной системы как социального объекта, а также как огромной сети социальных систем, функционирующих на значительной по своей географической широте территории страны.

Особую проблему при этом составляет обеспечение большей информационной открытости и обмена знаниями между обучающимися и преподавателями, а также другими субъектами системы - носителями знаний. В настоящий момент такой процесс носит в значительной мере неформальный характер, а в официальном формате носит элементы контрольных мероприятий или оттенок 
формализма, отчетности, нивелирующий его ресурсно-знаниевый потенциал. Решение этой проблемы видится путем более активного внедрения таких социальных технологий, как $[2,5$, 6 и др.]:

1) организации и проведения учебных занятий самими обучающимися для других групп, классов, направлений с целью обмена и расширения знаниями (в т.ч. в межпредметном формате). Такая практика позволила бы школьникам, получить опыт профессиональной деятельности, опыт социального взаимодействия и обмена знаниями, их накопления и репродукции под руководством высококвалифицированного преподавателя (преподавателей различных дисциплин), который в свою очередь имеет возможность передать накопленные знания в области подготовки и организации занятий;

2) применение технологий «сторителлинга» ( от англ. story telling - рассказ историй), в процессе которого обучающиеся (как и педагоги и т.д.) могли бы информировать других субъектов образования о результатах той или иной социально-практической деятельности, выполнения научноисследовательской работы, участия на конференции или конкурсе. При этом изложение положительных результатов и позитивные эмоции рассказчиков может служить дополнительной мотивацией других для участия в аналогичных видах деятельности;

3) предоставления условий (виртуальный портал, «облачные хранилища») для взаимодействия школьников, выпускников, а также преподавателей и других субъектов, участвующих в жизни образовательного заведения и процессе накопления знаний, в целях обмена полезной информацией, опытом, знаниями.

Безусловно, что такие мероприятия будут требовать особого внимания к процессу стимулирования мотивации обучающихся и педагогов, других субъектов общего образования, к дополнительному социальному взаимодействию, коммуникации и передаче знаний. При этом поощрения за поддержку обучения и развития знаний могут носить как материальный, так и нематериальный характер (например, общественное признание инновационности вклада, опыта, открытого или переданного знания, эффективности подобной деятельности и т.д.). Следует отметить, что в настоящий момент современная система мотивирования в системе общего образования в данном направлении находится не просто на этапе становления, а фактически на «нулевой стадии», требуя специальной теоретико-методологической и практической разработки данного вопроса.

В то же время необходимо признать, ч то в деятельности современных учебных заведений системы общего образования в РФ сегодня постепенно уже начинают применяться многие социальные технологии управления знаниями, заимствованные из бизнес-сферы, где концепция управления знаниями с позиции социального подхода к управлению развивается в течение более длительного периода. В частности, предпринимаются попытки (пусть и не в полном масштабе) внедрения технологии «обучающейся организации», ключевыми особенностями которой являются системное мышление и общее видение стратегии всеми субъектами организации; постоянное совершенствование личного уровня и командное обучение; доступность и полнота информации, открытость деятельности организации для всех субъектов; делегирование полномочий и власти; эффективные коммуникации внутри организации; развитая культура обучения, наставничества и передачи знаний.

В деятельности современных объектов системы общего образования в РФ также фрагментарно используются такие социальные технологии управления знаниями, как:

1) создание социальных сетей или ведение блогов для обмена опытом и знаниями между сотрудниками образовательных заведений; между руководителями, заместителями, методистами, между обучающимися и педагогами, родителями;

2) накопление и издание передового опыта и лучшей методики в деятельности сотрудников и подсистем образовательных заведений для последующего использования;

3) создание и взаимодействие «сетевых методических сообществ», «сообществ практиков» и других объединений с целью обмена знаниями и повышения профессионального уровня и качества образовательного процесса;

4) наставничество при решении коллективных задач и организации помощи новым сотрудникам, обучающимся, родителям, молодым специалистам и т.д.

Следует подчеркнуть, что в настоящее время во многих российских общеобразовательных организациях применяются такие социальные технологии управления знаниями, как «мозговой штурм» для решения стратегических задач, широко внедряется системы менеджмента качества, обучения и повышения квалификации управленческого и преподавательского состава, в том числе и на внутренних методологических семинарах, тренингах, когда сотрудники делятся собственным опытом и совместно вырабатывают новые способы организации образовательного процесса, решения проблемных ситуаций [8].

Кроме того, как уже подчеркивалось, использование социальных технологий управления знаниями в деятельности общеобразовательных организаций предполагает активное и непрерывное взаимодействие с внешней средой: работодателями, научно-исследовательскими центрами и институтами, общественными и государственными организациями, их представителями образовательными организациями дополнительного образования и др.

Социальные технологии в управлении знанием в системе общего образования также связаны с компьютеризацией и автоматизацией образования. Автоматизация управления знаниями в системе 
общего образования на федеральном уровне связана сегодня с развитием отраслевой интегрированной автоматизированной информационной системой (ИАИС), объединяющей Министерство просвещения РФ, образовательные организации, органы управления образованием на всех уровнях [3]. Все более распространенным инструментом социального управления знаниями выступают информационнокоммуникационные технологии (ИКТ), позволяющие создать единое открытое и доступное информационное пространство, связывающее деятельность различных подсистем общеобразовательного заведения или групп заведений и их субъектов [4]. В частности, речь идет об использовании специализированных информационных управляющих систем. Такие системы включают в себя не только средства обработки документов, но и системы управления базами данных, экспертные системы, современные средства коммуникаций и многое другое (в числе используемых в РФ систем, включающих подсистемы управления знаниями и их отдельные элементы, в частности, выделяются системы «Параграф: Учебное заведение ХХІ»; АСУ «Школа»; «NetШКОЛА», АИС «Сетевой город. Образование» и др.) [3]. Автоматизация управления ведет к развитию и использованию интеллектуальных обучающих систем (ИОС) в образовательном процессе как социальных технологий управления знаниями. В сравнении с традиционными занятиями ИОС обладают рядом преимуществ: а) повышают эффективность обучения, приближая его качество к уровню индивидуальных занятий с преподавателем и б) позволяют работать с каждым на индивидуальном уровне, учитывая его особенности, такие, как: начальный уровень, темп усвоения информации и обретения навыков, конечная цель обучения и т.п. Социальные технологии в управлении системой знаний в общем образовании также в настоящее время базируются на инструментарии Глобальной сети - Интернета, которая объединяет людей в единое глобальное социальное сообщество пользователей по различным сферам человеческой жизнедеятельности, аккумулируя и распространяя накопленные ими знания. Однако, наличие современной базы данных, накапливающей передовой опыт и знания субъектов, карты знаний, хранящей сведения о носителях определенных видов знаний, инструментов Глобальной сети, в т.ч. форумов и on-line сообществ и т.д. само по себе не гарантирует достижения стратегических целей общеобразовательного заведения и повышения его конкурентоспособности в системе образования и социуме, без участия человеческих ресурсов, но может существенно этому способствовать, создавая необходимую инфраструктуру для успешного превращения знаний в интеллектуальный капитал самого заведения и его выпускников.

Противоречивость развития социальных технологий управления знаниями в общем образовании в современных российских условиях, на наш взгляд, следует определить пока еще недостаточно готовностью общества, в особенности педагогического сообщества, администрации учебных заведений, к активной интеграции социальных технологий в его жизнедеятельность. Ситуация осложняется отсутствием нормативно-правовой базы, регламентирующей реализацию социальнотехнологических процессов. Социальные технологии пока еще не заняли надлежащего места в качестве предмета теоретической мысли в управлении знаниями в общем образовании, как и управление знаниями в образовании в целом. Следует указать также на тот факт, что пока еще не существует достоверных прогностических разработок, раскрывающих перспективы социально-технологической активности и ее вероятностных последствий. Постепенная активизация внедрения социальных технологий в управление знаниями в сфере общего образования свидетельствует о возрастающих социальных потребностях общества, нуждающегося в модернизации системы образования при одновременном сохранении ее и собственной идентичности. Одновременно социальные технологии встречаются с сохраняющейся стереотипностью восприятия (например, как чуждые элементы производственной, бизнессферы, разрушающие процессы гуманитаризации и интеллектуализации) и неоравданным консерватизмом, препятствующим их развитию.

Таким образом, можно заключить, что возможность применения социальных технологий управления знаниями в системе общего образования является сегодня в российских условиях сложной, многоаспектной областью и требует дальнейшего исследования. Внедрение менеджмента знаний в деятельности общеобразовательных организаций страны требует глубокого, системного анализа внешней и внутренней среды каждого отдельно взятого учебного заведения, адаптации инструментов управления знаниями к конкретным организационным и социокультурным особенностям образовательной орагинзации. Такой «индивидуальный» подход, несомненно, обеспечит эффективное создание современной инновационной информационной среды, непрерывно пополняемого знаниевого потенциала общеобразовательных заведений при сохранении лучших традиций отечественной школы и в контексте применения перспективных инструментов методологии социального подхода к управлению знаниями.

\section{Список литературы}

Буторина А.А. Инновационные социальные технологии / А.А.Буторина, Н.А.Соловьева и др. Ярославль: ЯрГУ, 2015. 160 с. ()1

Жилина А.И. Модель управления знаниями в современной системе образования // 
Царскосельские чтения. 2014. Т.2. № XVIII. С. 89101.(9)

Лупанов В.Н. Социальные технологии в системе управления открытым образованием [Электронный источник]// Современные проблемы науки и образования. 2008. № 3. URL: http://scienceeducation.ru/ru/article/view?id=736 (дата обращения: 25.10.2019).

Нестик Т.А. Социальные аспекты управления знаниями // Инновационное развитие. Экономика, интеллектуальные ресурсы, управление знаниями / под ред. Б.З. Мильнера. М.: ИНФРА-М, 2012. С. 530-544. (25)
Попова Ю.М. Социологический и социальный подходы к управлению знаниями в системе образования. М.: Праксис, 2017. 110 с. (32)

Харитонова В.Н. Возможности применения концепции управления знаниями в системе высшего образования [Электронный источник] // Global International Scientific Project. 2018. URL: http://gisap.eu/ru/node/1057 (дата обращения: 11.10.2019) (39)

Metcalfe A.S. Knowledge Management and Higher Education: A Critical Analysis. L.: Information Science Publishing, 2016. 300 p.

Serrat O. Building a Learning Organization // Knowledge Solutions. 2009. No. 46. Pp.41-44.

УДК $364.054 .3+376$

ГРНТИ 04.51 .65

\title{
ДЕТИ С ОГРАНИЧЕННЫМИ ВОЗМОЖНОСТЯМИ ЗДОРОВЬЯ КАК ОБЪЕКТ ПРОЕКТНОЙ
} ДЕЯТЕЛЬНОСТИ БЛАГОТВОРИТЕЛЬНОГО ФОНДА

Мустаева Флюра Альтафовна,

доктор сочиологических наук, профессор БГПУ им. М. Акмуллье, ведущий специиалист БФ «Металлург»;

Степанова Ирина Николаевна, заместитель директора БФ «Металлург»; Ларина Екатерина Владимировна,

зав. детским отделом БФ «Металлург», Благотворительный фонд «Металлург», г. Магнитогорск

\section{CHILDREN WITH DISABILITIES AS AN OBJECT OF PROJECT ACTIVITY OF A CHARITABLE FUND}

\author{
Mustaeva Flyura Al'tafovna, \\ Doctor of Sociology, \\ Professor of BSPU named after M. Akmullah, \\ Leading Expert of $C F$ «Metallurg»; \\ Stepanova Irina Nikolaevna, \\ Vice-director of $C F$ «Metallurg»; \\ Larina Ekaterina Vladimirovna, \\ Head of the Children's Department of CF «Metallurg», \\ the Charitable Fund «Metallurg», Magnitogorsk
}

\section{АННОТАЦИЯ}

Социальная поддержка семей, воспитывающих детей с ограниченными возможностями здоровья, актуальна сегодня как для государственных учреждений, так и некоммерческих организаций. В статье раскрывается роль благотворительного фонда в социализации детей-инвалидов. Используются опросные методы исследования (анкетирование, фокусированное интервью), результаты которых подтверждают теоретические положения авторов статьи. Делается вывод о необходимости сотрудничества семьи, государства и некоммерческого сектора в воспитании и социализации детей с ограниченными возможностями здоровья.

\section{ABSTRACT}

Social support of families bringing up children with disabilities is relevant for both public institutions and non-profit organizations. The article reveals the role of a charitable fund in socialization of children with disabilities. Survey methods (questionnaire, focused interview) were used, the results of which confirm the theoretical positions of the authors of the article. The conclusion is made about the need for cooperation between a family, the state and non-profit sector in education and socialization of children with disabilities.

Ключевые слова: дети с ограниченными возможностями здоровья, социализация, социальная поддержка семьи, благотворительный фонд, социальный проект. project.

Key words: children with disabilities, socialization, social support of a family, a charitable fund, a social 